\title{
Exploration of IMDC model in patients with metastatic renal cell carcinoma using targeted agents: a meta-analysis
}

\author{
Guiya Jiang ${ }^{1,2}$, Shuqiu Chen ${ }^{1,2}$, Ming Chen ${ }^{1,2}$ \\ 1 School of Medicine, Southeast University, China; 2 Department of Urology, Southeast University, \\ Zhongda Hospital, NanJing, 210009, China
}

\section{ABSTRACT}

Purpose: To explore the International Metastatic Renal Cell Carcinoma Database Consortium (IMDC) model application for predicting outcome of patients with metastatic renal cell carcinoma using targeted agents.

Materials and Methods: We performed a literature review of 989 articles. The selecting process used preferred reporting items for systematic reviews and meta-analyses (PRISMA). All included studies were assessed by Newcastle-Ottawa scale. Results of individual studies were pooled using Stata 14.0 software.

Results: A total of 17 articles were included. Most articles provided univariate and multivariate analysis of IMDC model prognosis. Combined HRs were 1.58 (95\% CI 1.34-1.82) and 3.74 (95\% CI 2.67-4.81) for univariate PFS of intermediate to favorable and poor to favorable respectively. In the category of multivariate PFS, combined HRs were 1.27 (95\% CI 0.99-1.56) and 2.29 (95\% CI 1.65-2.93) with intermediate to favorable and poor to favorable respectively. Regarding univariate OS, combined HRs were 1.93 (95\% CI 1.62-2.24) and 6.25 (95\% CI 4.18-8.31) with intermediate to favorable and poor to favorable respectively. With multivariate OS, combined HRs were 1.32 (95\%CI 1.04-1.59) and 2.35 (95\%CI 1.69-3.01) with intermediate to favorable and poor to favorable respectively.

Conclusion: In summary, analysis of currently available clinical evidence indicated that IMDC model could be applied to classify patients with metastatic renal cell carcinoma using targeted agents. However, different types of targeted agents and various areas could affect the accuracy of the model. There was also a difference in predicting patients' PFS and OS.

\section{ARTICLE INFO}

Shuqiu Chen

http://orcid.org/0000-0003-4117-1917

Keywords:

Carcinoma, Renal Cell; Meta-

Analysis [Publication Type];

Prognosis

Int Braz J Urol. 2020; 46: 328-40

Submitted for publication:

June 27, 2019

Accepted after revision:

October 22, 2019

Published as Ahead of Print:

December 30, 2019

\section{INTRODUCTION}

Renal cell carcinoma (RCC) represents approximately $3 \%$ of all cancers, with the highest incidence occurring in western countries. Generally, during the last two decades, there has been an annual increase of 2\% in incidence both worldwide and in Europe, leading to approximately 99, 200 new RCC cases and 39.100 kidney cancer-related deaths within the European Union in 2018 (1). According to the 2019 tumor statistics, there were 44.120 new kidney cancer men and 29.700 women in the United States, with the incidence rates being third and eighth respectively (2). Although most RCC cases are diagnosed at an early stage, approximately $20 \%$ of patients undergoing curati- 
ve nephrectomy will subsequently develop metastasis during the follow-up period (3). Many new therapeutic drugs have emerged, such as immune checkpoint drugs based on PD-1/PDL1 or CTLA4 as representative drugs, targeted agents are still the mainstream drugs for the treatment of metastatic renal cell carcinoma. Because of the poor prognosis of metastatic renal cell carcinoma, it is important to choose appropriate prognostic factors for communication with patients and their families, to determine treatment options, and to group people in clinical trials. The most widely used prognostic models for the prognosis of metastatic renal cancer is International Metastatic Renal Cell Carcinoma Database Consortium (IMDC) model (4). IMDC model was based on prognostic data from populations treated with various targeted drugs (5). Although the applicability of the model has been verified by some articles like Kwon's article (6), there are also articles like Peltola's (7) article that provide different conclusions. Therefore, we conducted this study to explore the IMDC model application for predicting outcome in patients with metastatic renal cell carcinoma using targeted agents.

\section{MATERIALS AND METHODS}

\section{Search strategy}

We performed a literature review of articles published before June 31, 2019 using the PubMed, Web of Sciences and Embase Databases. The main search terms used were "metastatic renal carcinoma”, "prognosis", "TKI”, "mTORi”, "sunitinib”, "sorafenib”, "pazopanib”, “axitinib”, "bevacizumab", "everolimus", " temsirolimus" et al. and their combinations. Additional references were identified from the reference list of each article. Two reviewers carried out this process independently. The selecting process using preferred reporting items for systematic reviews and meta-analyses (PRISMA) (8) statement was exhibited in Figure- 1 following the inclusion and exclusion criteria.

\section{Inclusion and Exclusion Criteria}

Inclusion criteria: (1) patients were confirmed with metastatic renal carcinoma pathologically, (2) used targeted agents, (3) provided survival outcome based on IMDC model such as progression-free survival (PFS) or overall survival (OS) with hazard ratio (HR) and 95\% confidence intervals $(95 \% \mathrm{CI})$.

Figure 1 - Selective process using preferred reporting items for systematic reviews and meta-analyses (PRISMA) statement.

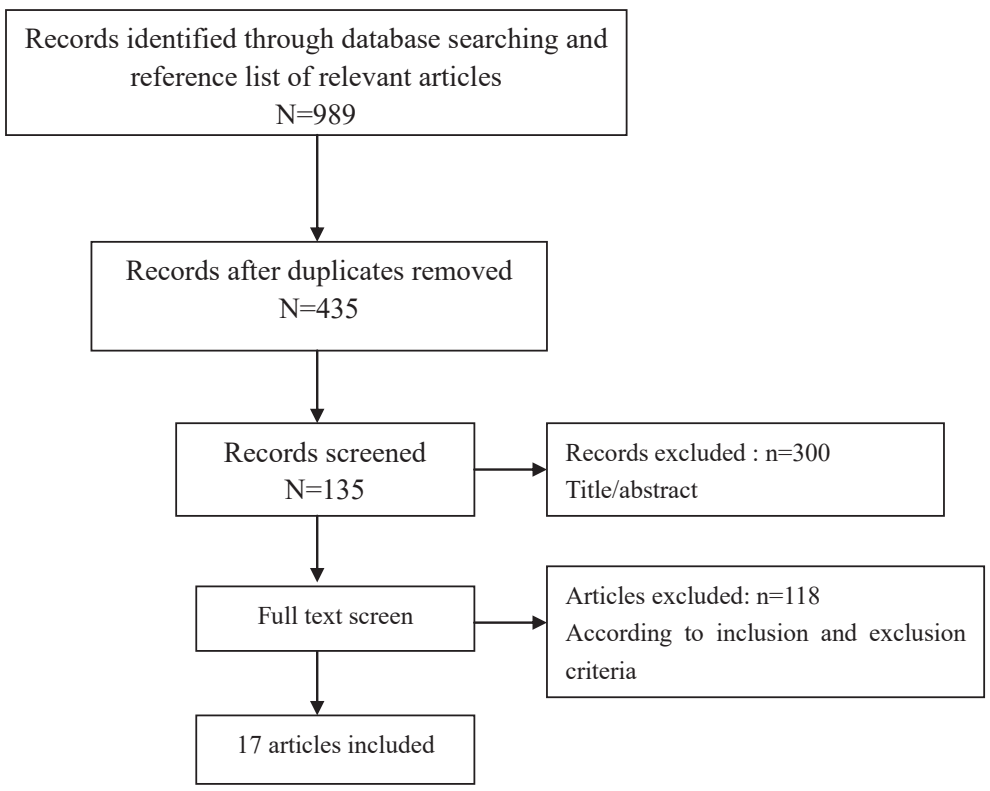


Exclusion criteria: (1) cohort of patients including other therapy like cytokine or immune checkpoint drugs, (2) articles providing data from the same population, (3) not in English.

\section{Data synthesis and analysis}

All included studies were assessed by Newcastle-Ottawa scale which provided a score from a possible total of nine scores. Key quality areas assessed included: (1) selection of study groups, (2) comparability of the groups, and (3) assessment of the outcome. High scores indicated high quality, a study with a score $\geq 6$ was regarded as high quality, while a score $<6$ was regarded as moderate or low quality (9). Results of individual studies were pooled using Stata 14.0 software (Stat Corp, College Station, TX, USA). Meta-analytical method was inverse variance method. We used the $\mathrm{I}^{2}$ statistic test to assess the heterogeneity between studies. $\mathrm{I}^{2}$ ranges are from $0 \%$ to $100 \%$ (a value of $0 \%$ represents no heterogeneity, $0 \%<\mathrm{I}^{2}<25 \%$ represents mild, 25\% $\leq \mathrm{I}^{2}<50 \%$ represents moderate, $75 \% \leq \mathrm{I}^{2}$ represents great heterogeneity). When $\mathrm{I}^{2}<50 \%$ or $\mathrm{P}_{\text {heterogeneity }}>0.1$, no obvious heterogeneity existed among the studies. To achieve a relatively conservative conclusion, the random-effects (RE) model was applied (10,11). Publication bias was assessed using a funnel plot and Egger's test. Sensitivity analysis was used to estimate the robustness of pooled results. $\mathrm{P}$ value $<0.05$ was considered to be statistically significant difference in studies.

\section{RESULTS}

\section{Characteristics of included studies}

According to the search strategy, 989 articles were retrieved from the electronic databases. By excluding duplicate reports and screening the abstracts, 135 articles were read by full text. The remaining articles were further excluded upon full-text review for several reasons, such as a lack of sufficient data to estimate HRs or duplicate publication in repeated cohorts. Finally, 17 articles were included for meta-analysis and the summary characteristics of articles were obtained (Table-1). Some articles provided different data from similar cohort of patients. Most articles provided univariate and multivariate analysis of HRs involving different factors for PFS and OS and we exhibited pooled results respectively.

\section{Univariate PFS}

There were 8 articles (12-19) including 1618 patients in this category, and Kawai's article (17) provided HR of poor to favorable only. Among these patients, 1454 were clear cell RCC and 163 were non clear cell RCC, favorable, intermediate and poor risk group has 401, 821, 336 patients respectively. Sunitinib was the most commonly used agent.

\section{Intermediate to favorable}

The combined HR was 1.58 (95\% CI 1.341.82 ) and the forest plot is shown in Figure-2. According to funnel plot and egger's test ( $p=0.308)$, there was no publication bias. And sensitivity analysis showed the result was robust. Subgroup analysis showed the model was applicable in both Asia and other areas (Supplementary Figure-1). Whether the cohort of patients all took sunitinib alone or part of patients took sorafenib or pazopanib or temsirolimus, the model could effectively distinguish between favorable and intermediate-risk group (Supplementary Figure-2).

\section{Poor to favorable}

The combined HR was 3.74 (95\% CI 2.674.81 ) and the forest plot is shown in Figure-2. According to funnel plot and Egger's test ( $p=0.911)$, there was no publication bias. And sensitivity analysis showed the result was robust. Subgroup analysis showed the model was reliable in both Asia and other areas (Supplementary Figure-1). Whether the cohort of patients all took sunitinib alone or part of patients took sorafenib or pazopanib or temsirolimus, the model could separate patients between favorable and poor-risk group (Supplementary Figure-2).

\section{Multivariate PFS}

There were 7 articles $(7,12,16,17,19$ 21) I ncluding 1087 patients in the category, and Kawai's article (17) still provided HR of poor to favorable only. Among these patients, 918 were clear cell RCC and 145 were non clear cell RCC, favorable, intermediate and poor risk groups have 
Table 1- The summary characteristics of 17 included articles.

\begin{tabular}{|c|c|c|c|c|c|c|c|c|}
\hline Author & Year & Country & Drug & Lines & Patient & Period & Follow-up (months) & \\
\hline Keizman & 2014 & Israel/US & Suni & combined & 278 & $\begin{array}{l}2004 / 2 / 1- \\
2013 / 3 / 31\end{array}$ & 55 & \\
\hline Yao & 2018 & China & suni or sora & NA & 231 & $2007-2017$ & NA & \\
\hline Peltola & 2017 & Finland & suni & first line & 137 & $\begin{array}{c}2006 / 10 / 18- \\
2012 / 5 / 31\end{array}$ & NA & \\
\hline Kawai & 2015 & Japan & suni & first line & 46 & $\begin{array}{c}\text { 2008/11/1- } \\
2013 / 7 / 1\end{array}$ & 21.2 & \\
\hline Giorgi & 2014 & Italy & suni & first line & 181 & 2006/2/1-2011/9/1 & 30.4 & \\
\hline Auclin & 2017 & France & evero & no first line & 124 & $\begin{array}{l}2007 / 2 / 1- \\
2014 / 11 / 1\end{array}$ & NA & \\
\hline Cai & 2017 & China & suni or sora & first line & 143 & 2006/3/1-2015/7/1 & 22 & \\
\hline Benoit & 2013 & Belgium/France & suni & first line & 200 & $\begin{array}{l}2005 / 1 / 1- \\
2012 / 10 / 1\end{array}$ & 67 & \\
\hline Bamias & 2014 & $\begin{array}{c}\text { Greece/France/ } \\
\text { Belgium }\end{array}$ & suni & first line & 186 & $\begin{array}{c}\text { 2005/10/1- } \\
\text { 2012/1/1 }\end{array}$ & 34.07 & \\
\hline Xia & 2017 & China & suni or sora & first line & 110 & $2005 / 3 / 1-2014 / 6 / 1$ & NA & \\
\hline Wang & 2016 & China & suni or sora & first line & 111 & $2005 / 3 / 1-2014 / 6 / 1$ & 19.7 & \\
\hline Miyake & 2016 & Japan & suni & first line & 50 & $2008 / 5 / 1-2013 / 7 / 1$ & 20 & \\
\hline Lin & 2019 & China & suni or sora & first line & 108 & $2005 / 3 / 1-2014 / 6 / 1$ & 23.35 & \\
\hline Kwon & 2013 & Korea & suni or sora & first or second & 106 & $2007 / 4 / 1-2012 / 7 / 1$ & NA & \\
\hline Lolli & 2016 & Italy & suni & first line & 335 & NA & 49 & \\
\hline You & 2016 & Korea & $\begin{array}{l}\text { suni, sora, pazo, or } \\
\text { temsi }\end{array}$ & first line & 325 & $\begin{array}{c}2006 / 11 / 1- \\
2013 / 6 / 1\end{array}$ & NA & \\
\hline Kim & 2018 & Korea & suni or pazo & first line & 554 & $\begin{array}{l}2012 / 1 / 1- \\
2016 / 11 / 1\end{array}$ & 16.4 & \\
\hline Author & $\operatorname{ccRCC}$ & nccRCC & Favorable & Intermediate & Poor & NOS & Outcome & $\begin{array}{c}\text { Survival } \\
\text { time(months) }\end{array}$ \\
\hline Keizman & 211 & 67 & 60 & 163 & 55 & 7 & $\mathrm{PFS} / \mathrm{OS}$ & $9 / 22$ \\
\hline Yao & 199 & 32 & 38 & 153 & 40 & 7 & OS & 17.5 \\
\hline Peltola & 105 & 15 & 29 & 74 & 31 & 7 & PFS/OS & $8.6 / 24.4$ \\
\hline Kawai & 46 & 0 & 2 & 26 & 18 & 6 & PFS/OS & $9.6 / 18.1$ \\
\hline Giorgi & 165 & 16 & 44 & 103 & 33 & 7 & PFS/OS & $11 / 25.5$ \\
\hline Auclin & 109 & 15 & 40 & 62 & 22 & 7 & OS & 12.9 \\
\hline Cai & 136 & 7 & 62 & 59 & 22 & 6 & $\mathrm{PFS} / 0 \mathrm{~S}$ & $11 / 27$ \\
\hline Benoit & 200 & 0 & 13 & 55 & 33 & 7 & PFS/OS & $12 / 20$ \\
\hline Bamias & 173 & 12 & 33 & 83 & 35 & 6 & OS & 20.96 \\
\hline Xia & 88 & 22 & 22 & 60 & 68 & 7 & $\mathrm{PFS} / \mathrm{OS}$ & $9.8 / 23.5$ \\
\hline Wang & 89 & 22 & 23 & 60 & 28 & 6 & $\mathrm{PFS} / \mathrm{OS}$ & NA \\
\hline Miyake & 40 & 4 & 10 & 29 & 11 & 6 & PFS/OS & $8.9 / 23.5$ \\
\hline Lin & 87 & 21 & 23 & 58 & 27 & 7 & $\mathrm{PFS} / \mathrm{OS}$ & NA \\
\hline Kwon & 85 & 21 & 18 & 54 & 16 & 7 & PFS/OS & $12 / 17.8$ \\
\hline Lolli & 315 & 20 & 117 & 176 & 42 & 6 & $\mathrm{PFS} / \mathrm{OS}$ & $14.2 / 32.7$ \\
\hline You & 293 & 31 & 81 & 179 & 65 & 7 & $\mathrm{PFS} / \mathrm{OS}$ & $16.2 / 26.1$ \\
\hline Kim & NA & NA & 114 & 345 & 90 & 6 & OS & $36.2 / 40.5$ \\
\hline
\end{tabular}

Suni $=$ sunitinib; Sora $=$ sorafenib; pazo $=$ pazopanib; evero $=$ everolimus; tems $\mathbf{i}$ = temsirolimus 
267, 588, and 229 patients respectively. Sunitinib was the most commonly used agent.

\section{Intermediate to favorable}

The combined HR was 1.27 (95\% CI 0.991.56) and the forest plot is shown in Figure-2. According to funnel plot and Egger's test ( $p=0.983)$, no publication bias was detected. And sensitivity analysis showed the result was not robust. When Lin and Keizman's article was omitted, the result changed to 1.43 (95\% CI 1.09-1.77) and 1.35 (95\% CI 1.01-1.69) respectively. Interestingly, only in Keizman's article the targeted agents were not used as first line therapy. Subgroup analysis showed the model was not applicable in both Asia and other areas (Supplementary Figure-1). Whether the cohort of patients all took sunitinib alone

\section{Figure 2 - Combined HRs of IMDC model from PFS.}

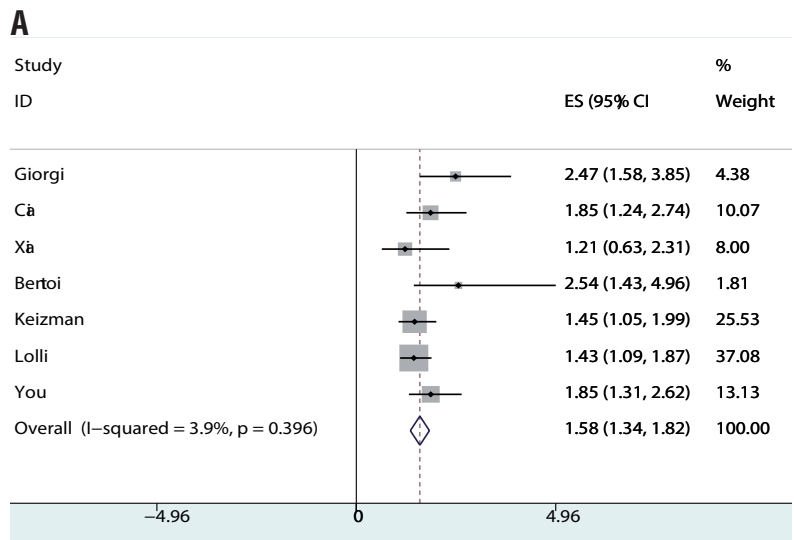

C

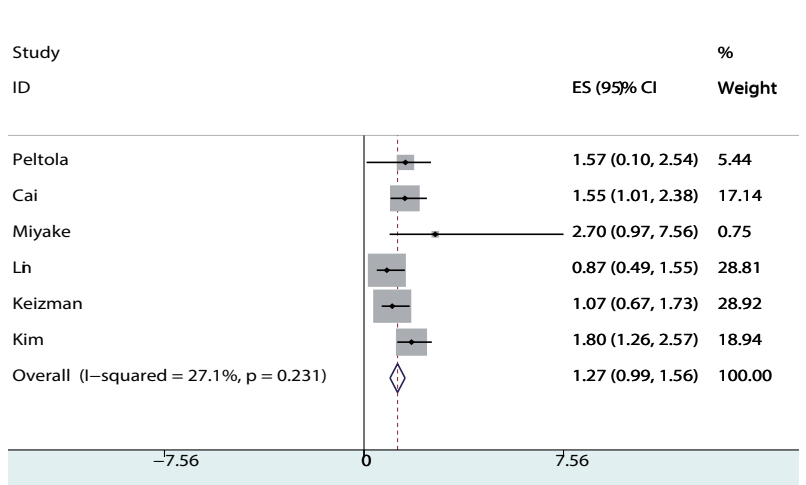

or part of patients took sorafenib or pazopanib or temsirolimus, the model was not efficient between favorable and intermediate-risk group (Supplementary Figure-2).

\section{Poor to favorable}

The combined HR was 2.29 (95\% CI 1.652.93) and the forest plot is shown in Figure-2. According to funnel plot and Egger's test $(p=0.962)$, no publication bias was detected. And sensitivity analysis showed the result was robust. Subgroup analysis showed the model was applicable in both Asia and other areas (Supplementary Figure-1). Whether the cohort of patients all took sunitinib alone or part of patients took sorafenib or pazopanib, the model was efficient to classify favorable and poor-risk group (Supplementary Figure-2).

\section{B}

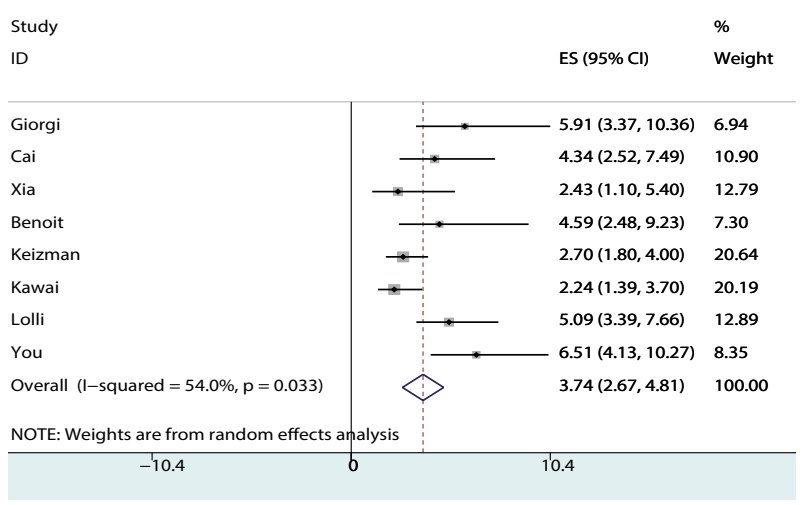

D

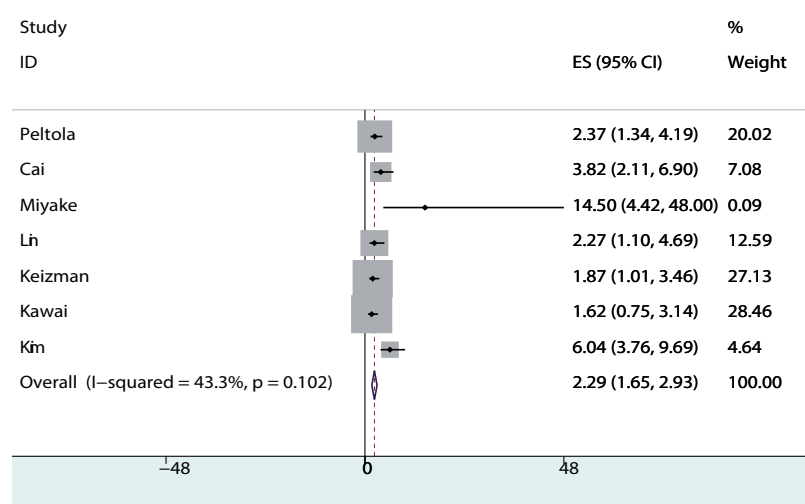

a) forest plot of univariate analysis of intermediate to favorable risk group; $\mathbf{b}$ ) forest plot of univariate analysis of poor to favorable risk group; c) forest plot of multivariate analysis of intermediate to favorable risk group; d) forest plot of multivariate analysis of poor to favorable risk group. 


\section{Univariate OS}

In all 10 articles $(6,12-14,16,18,18,22-24)$ including 2419 patients in the category, among these patients, 1667 were clear cell RCC and 196 were non clear cell RCC. It was unfortunate that Kim's article did not provide specific number of patients with different pathological types. Favorable, intermediate and poor risk group had 565, 1227, and 419 patients respectively.

\section{Intermediate to favorable}

The combined HR was 1.93 (95\% CI 1.622.24) and the forest plot is shown in Figure-3. According to funnel plot and Egger's test ( $\mathrm{p}=0.194)$, no publication bias was detected. Sensitivity analysis showed the result was robust. Subgroup analysis

Figure 3 - Combined HRs of IMDC model from OS.

A

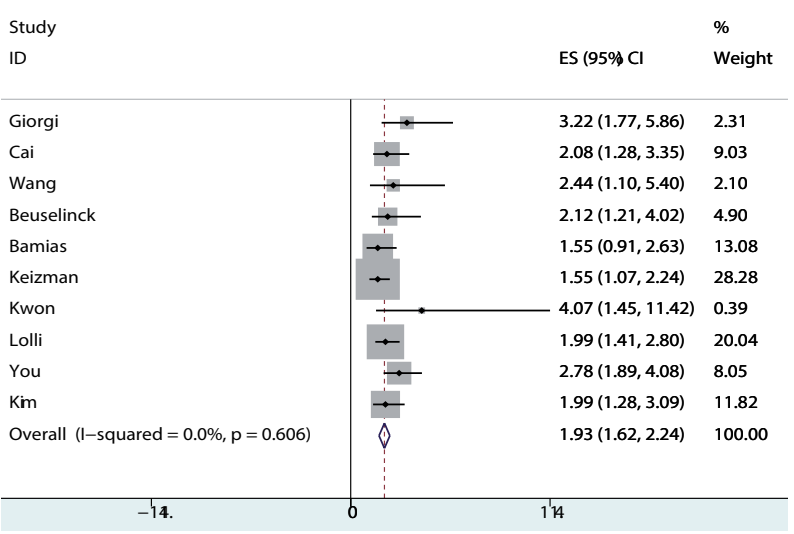

\section{C}

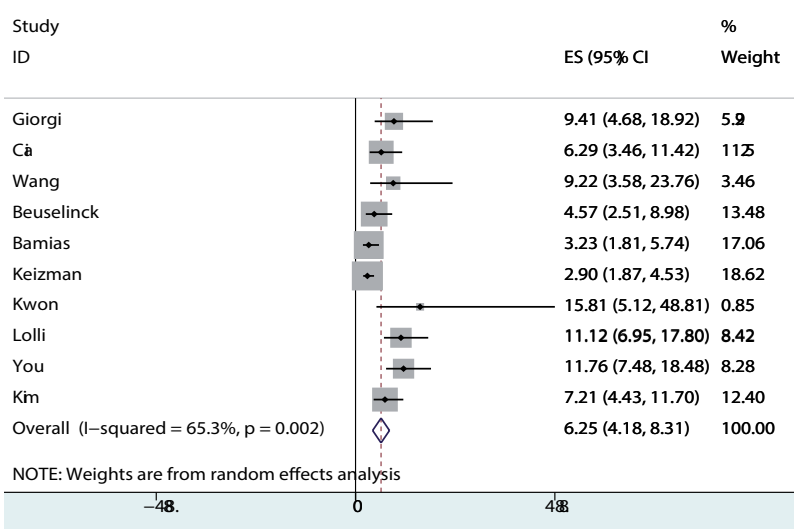

showed the model was applicable in both Asia and other areas (Supplementary Figure-3). Whether the cohort of patients all took sunitinib alone or part of patients took sorafenib or pazopanib or temsirolimus, the model was efficient to classify favorable and intermediate-risk group (Supplementary Figure-4).

\section{Poor to favorable}

The combined HR was 6.25 (95\% CI 4.188.31) and the forest plot is shown in Figure-3. According to funnel plot and Egger's test ( $p=0.596$ ), no publication bias was detected. Sensitivity analysis showed the result was robust. Subgroup analysis showed the model was applicable in both Asia and other areas (Supplementary Figure-3). Whether the cohort of patients all took sunitinib alone or part of

\section{B}

\begin{tabular}{|c|c|c|c|}
\hline Study & & & $\%$ \\
\hline ID & & ES $(95 \% \mathrm{Cl}$ & Weight \\
\hline Peltola & $\leftarrow$ & $1.28(0.76,2.16)$ & 15.30 \\
\hline Cai & $\rightarrow$ & $1.98(1.18,3.32)$ & 6.55 \\
\hline Miyake & 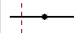 & $2.69(0.61,11.90)$ & 0.24 \\
\hline Yao & 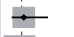 & $1.45(0.73,2.89)$ & 6.38 \\
\hline Ln & $\rightarrow$ & $1.19(0.66,2.17)$ & 13.13 \\
\hline Keizman & $\leftarrow$ & $1.08(0.66,1.80)$ & 23.07 \\
\hline Auclin & $\leftarrow$ & $1.12(0.70,1.80)$ & 24.78 \\
\hline You & $\rightarrow$ & $2.00(1.29,3.12)$ & 8.94 \\
\hline Km & 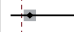 & $1.81(0.66,4.97)$ & 1.61 \\
\hline Overall (I-squared $=0.0 \%, p=0.714)$ & $\theta$ & $1.32(1.04,1.59)$ & 100.00 \\
\hline-19. & & $B$ & \\
\hline
\end{tabular}

D

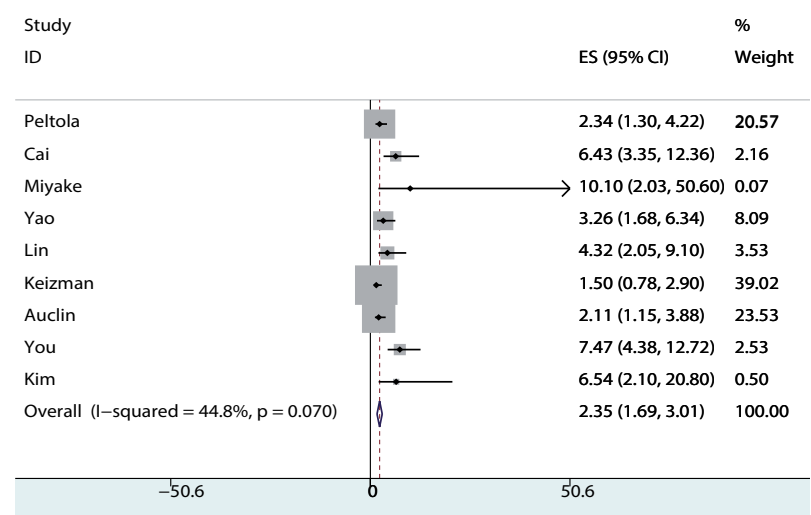

a) forest plot of univariate analysis of intermediate to favorable risk group; b) forest plot of univariate analysis of poor to favorable risk group; c) forest plot of multivariate analysis of intermediate to favorable risk group; d) forest plot of multivariate analysis of poor to favorable risk group. 
patients took sorafenib or pazopanib or temsirolimus, the model was efficient to classify favorable and poor-risk group (Supplementary Figure-4).

\section{Multivariate OS}

A total of 9 articles $(7,12,16,19-22,25$, 26) including 1950 patients in the category, among these patients, 1180 were clear cell RCC and 192 were non clear cell RCC. Kim's article not providing specific number of patients with different pathological types was also included. Favorable, intermediate and poor risk groups had 457, 1122, and 363 patients, respectively.

\section{Intermediate to favorable}

The combined HR was 1.32 (95\% CI 1.04$1.59)$ and the forest plot is shown in Figure-3. According to funnel plot and Egger's test ( $p=0.551)$, no publication bias was detected. Sensitivity analysis showed the result was not robust. When Cai's article and You's article were omitted respectively, combined HR became not significant. Subgroup analysis showed the model was applicable in Asia. However, in other areas the model could not differentiate patients sufficiently (95\% CI 0.80-1.49) (Supplementary Figure-3). Various types of targeted agents from cohort of patients affected the model's effectiveness to classify in favorable and intermediate-risk groups (Supplementary Figure-4).

\section{Poor to favorable}

The combined HR was 2.35 (95\% CI 1.693.01) and the forest plot is shown in Figure-3. According to funnel plot and Egger's test $(p=0.555)$, no publication bias was detected. Sensitivity analysis showed the result was robust. Subgroup analysis showed the model was applicable in both Asia and other areas (Supplementary Figure-3). The model's efficiency was not reliable when it was applied to different types of targeted agents in the cohort of patients (Supplementary Figure-4).

\section{DISCUSSION}

IMDC model including six independent factors such as KPS $<80 \%$, time from diagnosis to treatment $<1$ year; hemoglobin $<$ LLN, Calcium $>$ ULN, Neutrophils <ULN, and Platelets $>$ ULN was first set in 2009 (5). After its occurrence, many studies applied it to make risk stratification of patients using targeted agents. However, there was not a systematic evaluation for the model. In-depth analysis of the existing literature was performed to explore the application of IMDC model. Interestingly, it was found that the model was also utilized to predict patient's PFS though it was first set to predict patient's overall survival. Actually, its application in predict patient's PFS had not been explored. This was the furst study to validate their application in the area.

Most incorporated articles provide univariate and multivariate analysis of prognostic factors. For meta-analysis, univariate pooling can best reflect potential valuable prognostic factors despite the possibility of combining confounding factors leading to repetitive effects. Multivariate merging may be inherently heterogeneous due to the inconsistencies in the variables included in each article. Conversely, the statistically significant prognostic factors obtained through this combination may be able to withstand the challenges of different conditions and could be widely used.

According to our analysis, IMDC model was able to classify patients to different risk group with various PFS and OS except in the category of intermediate to poor risk group for PFS (95\% CI 0.99-1.56). Simultaneously, the combined HR was larger in the category of univariate analysis than those in the category of multivariate analysis. It possibly suggested that IMDC model was affected by other existing factors. In other words, it should be taken into account when the model is incorporated as one independent prognostic factor to reform a new prognostic model. In addition, we also explored the applicability of this model in different drugs and different populations. There are a variety of targeted drugs, and we have included studies that simply use sunitinib as a treatment, as well as a combination of sorafenib, pazopanib, and even mTORi, such as temsirolimus. Based on the subgroup analysis, IMDC model was reliable on the univariate analysis of PFS and OS and multivariate analysis of PFS limited in the poor to favorable risk group. Its applicability was not stable in the category of multivariate analysis of PFS located in the intermediate to favorable risk group 
and multivariate analysis of OS. When it came to the area targeted agents were used, various results existed in different conditions. IMDC model was reliable on the univariate analysis of PFS and OS and multivariate analysis of PFS and OS limited in the poor to favorable risk group both in Asia and other areas. It was not reliable in the category of multivariate analysis of PFS located in the intermediate to favorable risk group both in Asia and other areas. However, it could be used in the multivariate analysis of OS in Asia not in other area. There were two main explanations for the difference. On one hand, unstable results were concentrated on the intermediate to favorable risk group, indicating the classification was not accurate enough. On the other hand, PFS results were more stable than OS results, indicating that OS was easier to be affected by other factors other than targeted drug therapy. There was no doubt that the number of studies included is an important factor affecting the outcome. More high-quality clinical studies could provide more robust results.

\section{Limitation and prospection}

The findings of this systematic review should be considered in the context of the available evidence, which may be limited by selection bias and follow-up as reflected in the strength of evidence ratings. Due to there was not enough articles available, the application of the model for specific country or race was not explored. Meanwhile, most of the involved patients were ccRCC, the reliability of the model for nccRCC needed more studies to verify. Additionally, most articles used targeted agents as first line therapy except Keizman's, Auclin's and Kwon's articles $(6,16,26)$, whether first line or second line of targeted therapy would influence the model was not explored. Although Heng's article (5) showed that there was no difference. And many other targeted agents such as axitinib were not covered in the included studies, leading to that the analysis was not particularly comprehensive. According to our analysis, the number of patients in the intermediate risk group was almost twice that of the other two groups, which was consistent with its initiative results (5). It indicated that a more specific subdivision could be made in the intermediate risk group.

\section{CONCLUSIONS}

In summary, our analysis of currently available clinical evidence indicated that IMDC could be applied to classify patients with metastatic renal cell carcinoma using targeted agents. However, different types of targeted agents and various areas could affect the accuracy of the model. There was also a difference in predicting patients' PFS and OS. Based on the limitations of both the studies evaluated and our meta-analysis, further well-designed studies are needed to draw a more definite conclusion as to the clinical significance of IMDC model.

\section{CONFLICT OF INTEREST}

None declared.

\section{REFERENCES}

1. Ljungberg B, Albiges L, Abu-Ghanem Y, Bensalah K, Dabestani $S$, Fernández-PelloS, et al. European Association of Urology Guidelines on Renal Cell Carcinoma: The 2019 Update. Eur Urol. 2019;75:799-810.

2. Siegel RL, Miller KD, Jemal A. Cancer statistics, 2019. CA Cancer J Clin. 2019:69:7-34.

3. Volpe A, Bollito E, Bozzola C, Di Domenico A, Bertolo R, Zegna $L$, et al. Classification of Histologic Patterns of Pseudocapsular Invasion in Organ-Confined Renal Cell Carcinoma. Clin Genitourin Cancer. 2016;14:69-75.

4. Powles T, Albiges L, Staehler M, Bensalah K, Dabestani S, Giles $\mathrm{RH}$, et al. Updated European Association of Urology Guidelines Recommendations for the Treatment of First-line Metastatic Clear Cell Renal Cancer. Eur Urol. 2017.

5. Heng DY, Xie W, Regan MM, Warren MA, Golshayan AR, Sahi $C$, et al. Prognostic factors for overall survival in patients with metastatic renal cell carcinoma treated with vascular endothelial growth factor-targeted agents: results from a large, multicenter study. J Clin Oncol. 2009;27:5794-9.

6. Kwon WA, Cho IC, Yu A, Nam BH, Joung JY, Seo HK, et al. Validation of the MSKCC and Heng risk criteria models for predicting survival in patients with metastatic renal cell carcinoma treated with sunitinib. Ann Surg Oncol. 2013;20:4397-404.

7. Peltola KJ, Penttilä $P$, Rautiola J, Joensuu $H$, Hänninen E, Ristimäki A, et al. Correlation of c-Met Expression and Outcome in Patients With Renal Cell Carcinoma Treated With Sunitinib. Clin Genitourin Cancer. 2017;15:487-494. 
8. Liberati A, Altman DG, Tetzlaff J, Mulrow C, Gøtzsche PC, Ioannidis JP, et al. The PRISMA statement for reporting systematic reviews and meta-analyses of studies that evaluate health care interventions: explanation and elaboration. J Clin Epidemiol. 2009;62:e1-34.

9. GA Wells, B Shea, D O'Connell, J Peterson, V Welch, M Losos, et al. Tugwell, The Newcastle-Ottawa Scale (NOS) for assessing the quality of nonrandomised studies in metaanalyses.

10. Ioannidis JP, Patsopoulos NA, Evangelou E. Heterogeneity in meta-analyses of genome-wide association investigations. PLoS One. 2007;2:e841.

11. Higgins JP, Thompson SG, Deeks JJ, Altman DG. Measuring inconsistency in meta-analyses. BMJ. 2003;327:557-60.

12. Cai W, Kong W, Dong B, Zhang J, Chen Y, Xue W, et al. Pretreatment Serum Prealbumin as an Independent Prognostic Indicator in Patients With Metastatic Renal Cell Carcinoma Using Tyrosine Kinase Inhibitors as First-Line Target Therapy. Clin Genitourin Cancer. 2017;15:e437-e446.

13. De Giorgi U, Rihawi K, Aieta M, Lo Re G, Sava T, Masini C, et al. Lymphopenia and clinical outcome of elderly patients treated with sunitinib for metastatic renal cell cancer. J Geriatr Oncol. 2014;5:156-63.

14. Beuselinck B, Vano YA, Oudard S, Wolter P, De Smet R, Depoorter $L$, et al. Prognostic impact of baseline serum C-reactive protein in patients with metastatic renal cell carcinoma (RCC) treated with sunitinib. BJU Int. 2014;114:81-9.

15. Xia Y, Liu L, Xiong Y, Bai Q, Wang J, Xi W, et al. Prognostic value of CC-chemokine receptor seven expression in patients with metastatic renal cell carcinoma treated with tyrosine kinase inhibitor. BMC Cancer. 2017;17:70.

16. Keizman D, Gottfried M, Ish-Shalom M, Maimon N, Peer A, Neumann $A$, et al. Active smoking may negatively affect response rate, progression-free survival, and overall survival of patients with metastatic renal cell carcinoma treated with sunitinib. Oncologist. 2014;19:51-60.

17. Kawai $Y$, Osawa $T$, Kobayashi $K$, Inoue $R$, Yamamoto $Y$, Matsumoto $\mathrm{H}$, et al. Factors Prognostic for Survival in Japanese Patients Treated with Sunitinib as First-line Therapy for Metastatic Clear Cell Renal Cell Cancer. Asian Pac J Cancer Prev. 2015;16:5687-90.

18. Lolli C, Basso U, Derosa L, Scarpi E, Sava T, Santoni M, et al. Systemic immune-inflammation index predicts the clinical outcome in patients with metastatic renal cell cancer treated with sunitinib. Oncotarget. 2016;7:54564-54571.
19. You D, Lee C, Jeong IG, Song C, Lee JL, Hong B, et al. Impact of metastasectomy on prognosis in patients treated with targeted therapy for metastatic renal cell carcinoma. J Cancer Res Clin Oncol. 2016;142:2331-8.

20. Miyake M, Kuwada M, Hori S, Morizawa Y, Tatsumi Y, Anai $\mathrm{S}$, et al. The best objective response of target lesions and the incidence of treatment-related hypertension are associated with the survival of patients with metastatic renal cell carcinoma treated with sunitinib: a Japanese retrospective study. BMC Res Notes. 2016;9:79.

21. Lin Z, Liu L, Xia Y, Chen X, Xiong Y, Qu Y, et al. Tumor infiltrating CD19(+) B lymphocytes predict prognostic and therapeutic benefits in metastatic renal cell carcinoma patients treated with tyrosine kinase inhibitors. Oncoimmunology. 2018;7:e1477461.

22. Kim MS, Chung HS, Hwang EC, Jung SI, Kwon DD, Hwang $\mathrm{JE}$, et al. Efficacy of First-Line Targeted Therapy in RealWorld Korean Patients with Metastatic Renal Cell Carcinoma: Focus on Sunitinib and Pazopanib. J Korean Med Sci. 2018;33:e325.

23. Wang J, Liu L, Qu Y, Xi W, Xia Y, Bai Q, et al. Prognostic Value of SETD2 Expression in Patients with Metastatic Renal Cell Carcinoma Treated with Tyrosine Kinase Inhibitors. J Urol. 2016;196:1363-1370.

24. Bamias A, Tzannis K, Papatsoris A, Oudard S, Beuselinck B, Escudier B, et al. Prognostic significance of cytoreductive nephrectomy in patients with synchronous metastases from renal cell carcinoma treated with first-line sunitinib: a European multiinstitutional study. Clin Genitourin Cancer. 2014;12:373-83.

25. Yao J, Xi W, Zhu Y, Wang H, Hu X, Guo J. Checkpoint molecule PD-1-assisted CD8(+) T lymphocyte count in tumor microenvironment predicts overall survival of patients with metastatic renal cell carcinoma treated with tyrosine kinase inhibitors. Cancer Manag Res. 2018;10:3419-3431.

26. Auclin E, Bourillon C, De Maio E, By MA, Seddik S, Fournier L, et al. Prediction of Everolimus Toxicity and Prognostic Value of Skeletal Muscle Index in Patients With Metastatic Renal Cell Carcinoma. Clin Genitourin Cancer. 2017;15:350-355.

Correspondence address: Shuqiu Chen

Zhongda hospital, Southeast University-Urology 87 Dingjiaqiao Road, Nanjing Nanjing 210009, China E-mail: chenshuqiuseu@163.com 
Supplementary Figure 1 - Subgroup analysis of area for PFS.

A

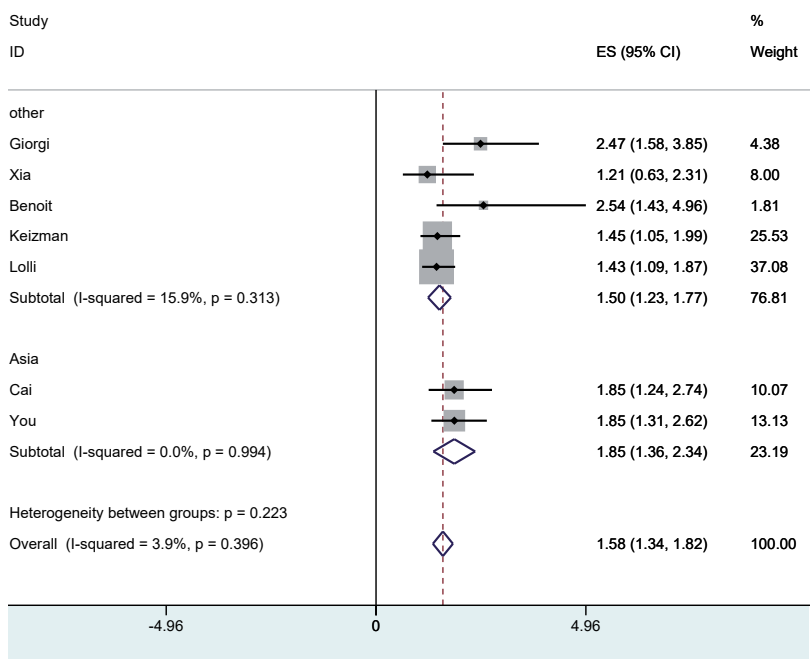

C

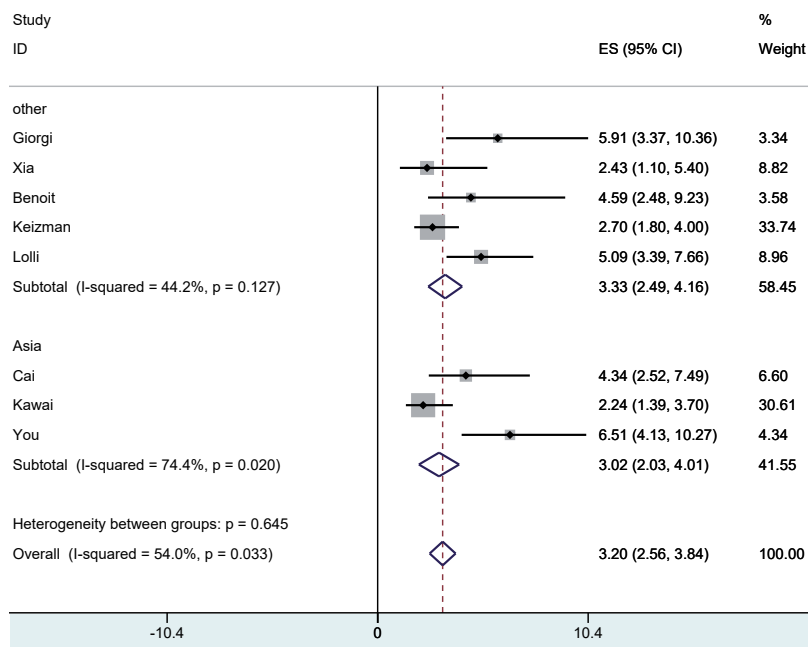

B

ID $\quad$ ES $(95 \% \mathrm{Cl}) \quad$ Weight

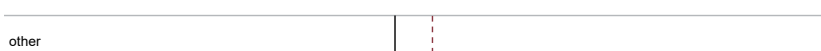

$\begin{array}{llll}\text { Peltola } & 1.57(0.10,2.54) & 7.45\end{array}$

Keizman

Subtotal $($ I-squared $=0.0 \%, p=0.462$

$1.07(0.67,1.73) \quad 26.32$

$1.15(0.66,1.64) \quad 33.77$

Asia

Cai

Miyak

Lin

Subtotal $(1-$ squared $=49.6 \%, p=0.114)$

Overall (1-squared $=27.1 \%, p=0.231$ )

NOTE: Weights are from random effects analysis

$-7.56$

7.56

D

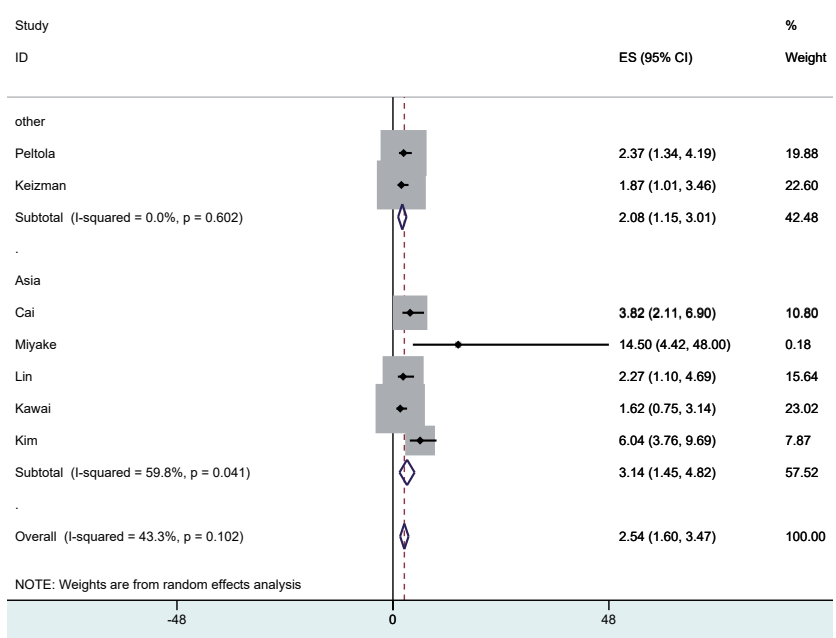

a) PFS univariate analysis of intermediate to favorable risk group for area; b) PFS univariate analysis of poor to favorable risk group for area; c) PFS multivariate analysis of intermediate to favorable risk group for area; d) PFS multivariate analysis of poor to favorable risk group for area 
Supplementary Figure 2 - Subgroup analysis of drug type for PFS.

A

\begin{tabular}{|c|c|c|c|}
\hline Study & & & $\%$ \\
\hline ID & & $\mathrm{ES}(95 \% \mathrm{Cl})$ & Weigh \\
\hline suni & & & \\
\hline Giorgi & $\rightarrow-$ & $2.47(1.58,3.85)$ & 4.38 \\
\hline Benoit & & $2.54(1.43,4.96)$ & 1.81 \\
\hline Keizman & & $1.45(1.05,1.99)$ & 25.53 \\
\hline Lolli & & $1.43(1.09,1.87)$ & 37.08 \\
\hline Subtotal $(I-$ squared $=29.5 \%, p=0.235)$ & & $1.53(1.25,1.82)$ & 68.80 \\
\hline suni+sora & & & \\
\hline Cai & & $1.85(1.24,2.74)$ & 10.07 \\
\hline Xia & $\rightarrow$ & $1.21(0.63,2.31)$ & 8.00 \\
\hline Subtotal $(I-$ squared $=18.3 \%, p=0.268)$ & & $1.57(1.01,2.12)$ & 18.07 \\
\hline suni, sora, pazo, or temsi & & & \\
\hline You & & $1.85(1.31,2.62)$ & 13.13 \\
\hline Subtotal (I-squared $=. \%, p=)$. & & $1.85(1.20,2.51)$ & 13.13 \\
\hline Heterogeneity between groups: $p=0.683$ & & & \\
\hline Overall $($ I-squared $=3.9 \%, p=0.396$ ) & $\diamond$ & $1.58(1.34,1.82)$ & 100.00 \\
\hline-4.96 & 0 & 4.96 & \\
\hline
\end{tabular}

C

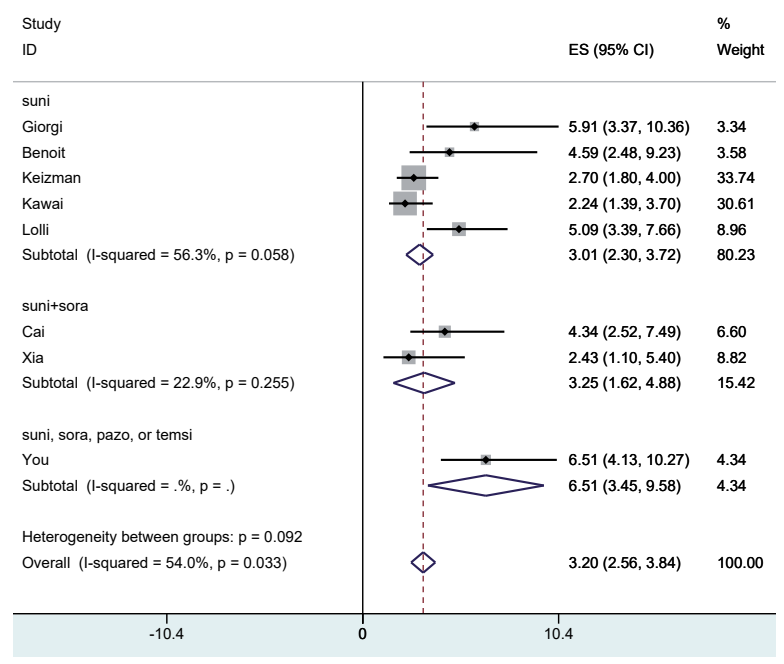

D

\section{B}

\begin{tabular}{|c|c|c|c|}
\hline \multicolumn{3}{|l|}{ Study } & $\%$ \\
\hline ID & & ES $(95 \% \mathrm{Cl})$ & Weight \\
\hline \multicolumn{4}{|l|}{ suni } \\
\hline Peltola & & $1.57(0.10,2.54)$ & 5.44 \\
\hline Miyake & & $2.70(0.97,7.56)$ & 0.75 \\
\hline Keizman & $\rightarrow$ & $1.07(0.67,1.73)$ & 28.92 \\
\hline Subtotal $(I-$ squared $=0.0 \%, p=0.503)$ & & $1.18(0.70,1.66)$ & 35.11 \\
\hline \multicolumn{4}{|l|}{ sunitsora } \\
\hline Cai & $\rightarrow$ & $1.55(1.01,2.38)$ & 17.14 \\
\hline Lin & $\rightarrow$ & $0.87(0.49,1.55)$ & 28.81 \\
\hline Subtotal $(I-$ squared $=57.7 \%, p=0.124)$ & Q & $1.12(0.70,1.54)$ & 45.95 \\
\hline \multicolumn{4}{|l|}{ sunitpazo } \\
\hline Kim & & $1.80(1.26,2.57)$ & 18.94 \\
\hline Subtotal (I-squared $=. \%, p=)$. & & $1.80(1.14,2.45)$ & 18.94 \\
\hline \multicolumn{4}{|l|}{ Heterogeneity between groups: $p=0.210$} \\
\hline Overall $(1-$ squared $=27.1 \%, p=0.231)$ & $\Delta$ & $1.27(0.99,1.56)$ & 100.00 \\
\hline-7.56 & & 56 & \\
\hline
\end{tabular}

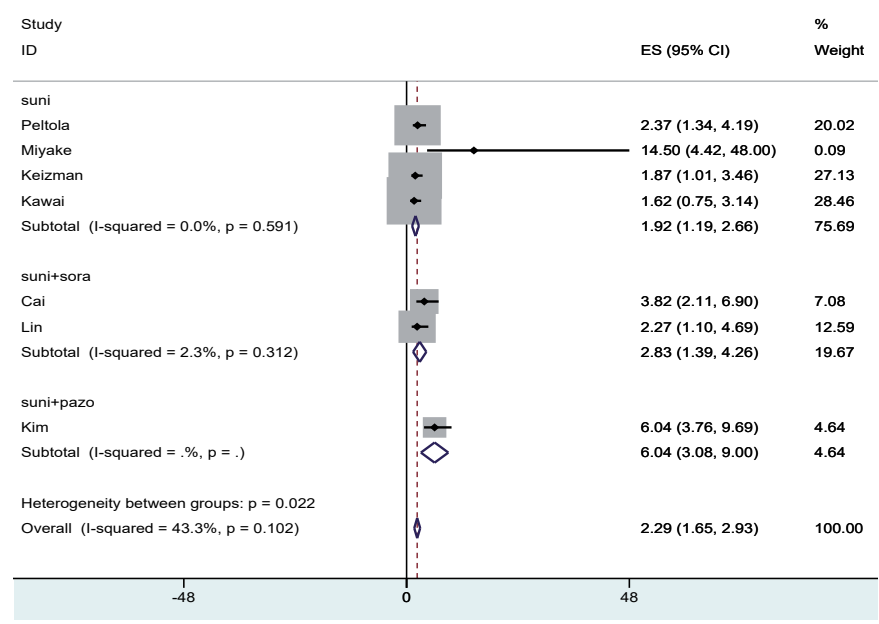

a) PFS univariate analysis of intermediate to favorable risk group for area; $\mathbf{b})$ PFS univariate analysis of poor to favorable risk group for area; c) PFS multivariate analysis of intermediate to favorable risk group for area; d) PFS multivariate analysis of poor to favorable risk group for area 
Supplementary Figure 3 - Subgroup analysis of area for OS.

A

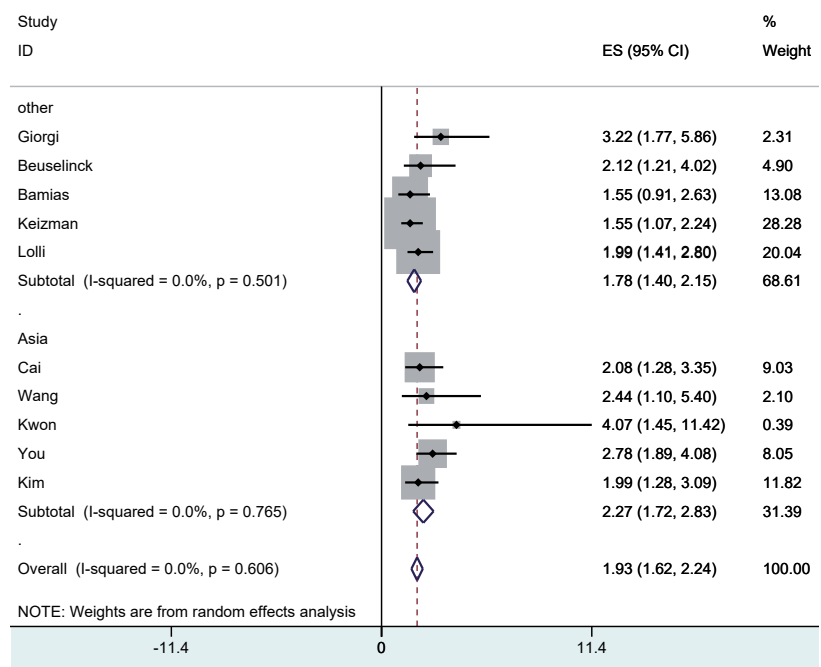

C

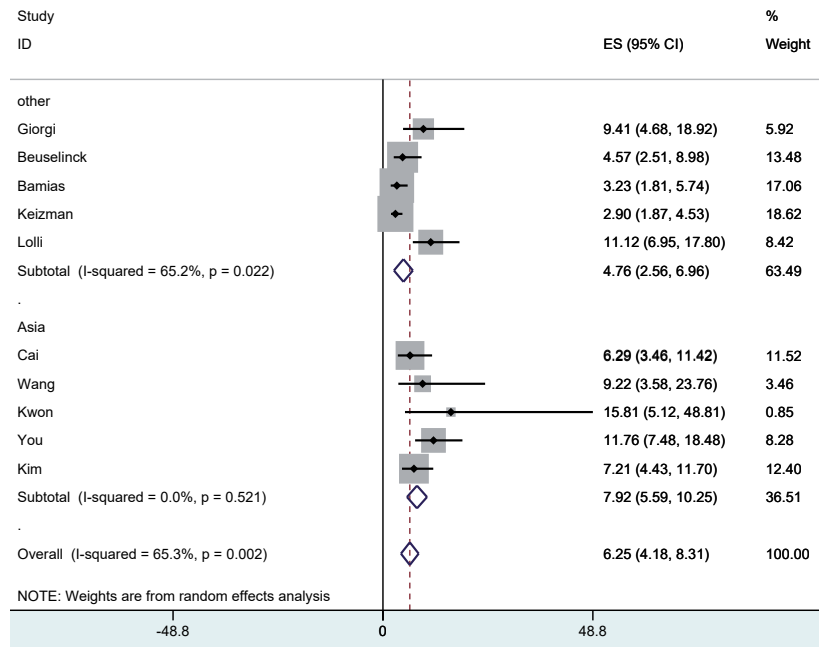

B

\begin{tabular}{|c|c|c|c|}
\hline Study & & & $\%$ \\
\hline ID & & ES $(95 \% \mathrm{Cl})$ & Weight \\
\hline other & 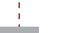 & & \\
\hline Peltola & $\rightarrow$ & $1.28(0.76,2.16)$ & 15.30 \\
\hline Keizman & $\leftarrow$ & $1.08(0.66,1.80)$ & 23.07 \\
\hline Auclin & $\leftarrow$ & $1.12(0.70,1.80)$ & 24.78 \\
\hline Subtotal (I-squared $=0.0 \%, p=0.904)$ & 0 & $1.14(0.80,1.49)$ & 63.14 \\
\hline & 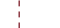 & & \\
\hline Asia & 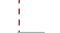 & & \\
\hline Cai & $\rightarrow$ & $1.98(1.18,3.32)$ & 6.55 \\
\hline Miyake & 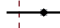 & $2.69(0.61,11.90)$ & 0.24 \\
\hline Yao & - & $1.45(0.73,2.89)$ & 6.38 \\
\hline Lin & $\leftarrow$ & $1.19(0.66,2.17)$ & 13.13 \\
\hline You & $\rightarrow$ & $2.00(1.29,3.12)$ & 8.94 \\
\hline Kim & is & $1.81(0.66,4.97)$ & 1.61 \\
\hline Subtotal (I-squared $=0.0 \%, p=0.761)$ & $\Delta$ & $1.61(1.16,2.06)$ & 36.86 \\
\hline & $i$ & & \\
\hline Overall $(1-$ squared $=0.0 \%, p=0.714$ ) & $\theta$ & $1.32(1.04,1.59)$ & 100.00 \\
\hline NOTE: Weights are from random effects analysis & 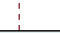 & & \\
\hline-11.9 & & .9 & \\
\hline
\end{tabular}

D

\begin{tabular}{|c|c|c|c|}
\hline \multicolumn{3}{|l|}{ Study } & \multirow{2}{*}{$\begin{array}{l}\% \\
\text { Weight }\end{array}$} \\
\hline ID & & ES $(95 \% \mathrm{Cl})$ & \\
\hline \multicolumn{4}{|l|}{ other } \\
\hline Peltola & $\leftarrow$ & $2.34(1.30,4.22)$ & 20.55 \\
\hline Keizman & - & $1.50(0.78,2.90)$ & 24.72 \\
\hline Auclin & - & $2.11(1.15,3.88)$ & 21.52 \\
\hline Subtotal (1-squared $=0.0 \%, p=0.611$ ) & $\theta_{1}$ & $1.88(1.15,2.61)$ & 66.79 \\
\hline & i & & \\
\hline \multicolumn{4}{|l|}{ Asia } \\
\hline Cai & : & $6.43(3.35,12.36)$ & 5.08 \\
\hline Miyake & $\rightarrow$ & $10.10(2.03,50.60)$ & 0.21 \\
\hline Yao & $\leftarrow$ & $3.26(1.68,6.34)$ & 13.25 \\
\hline Lin & $1+$ & $4.32(2.05,9.10)$ & 7.54 \\
\hline You & $i$ & $7.47(4.38,12.72)$ & 5.79 \\
\hline Kim & $i$ & $6.54(2.10,20.80)$ & 1.34 \\
\hline Subtotal $(1-$ squared $=0.0 \%, p=0.534)$ & 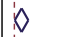 & $4.65(3.03,6.26)$ & 33.21 \\
\hline & 1 & & \\
\hline Overall (I-squared $=44.8 \%, p=0.070)$ & 6 & $2.93(1.82,4.04)$ & 100.00 \\
\hline NOTE: Weights are from random effects analysis & & & \\
\hline $\begin{array}{l}1 \\
-50.6\end{array}$ & & 6 & \\
\hline
\end{tabular}

a) OS univariate analysis of intermediate to favorable risk group for area; $\mathbf{b})$ OS univariate analysis of poor to favorable risk group for area; $\mathbf{c}$ ) OS multivariate analysis of intermediate to favorable risk group for area; d) OS multivariate analysis of poor to favorable risk group for area. 
Supplementary Figure 4 - Subgroup analysis of drug type for OS.

A

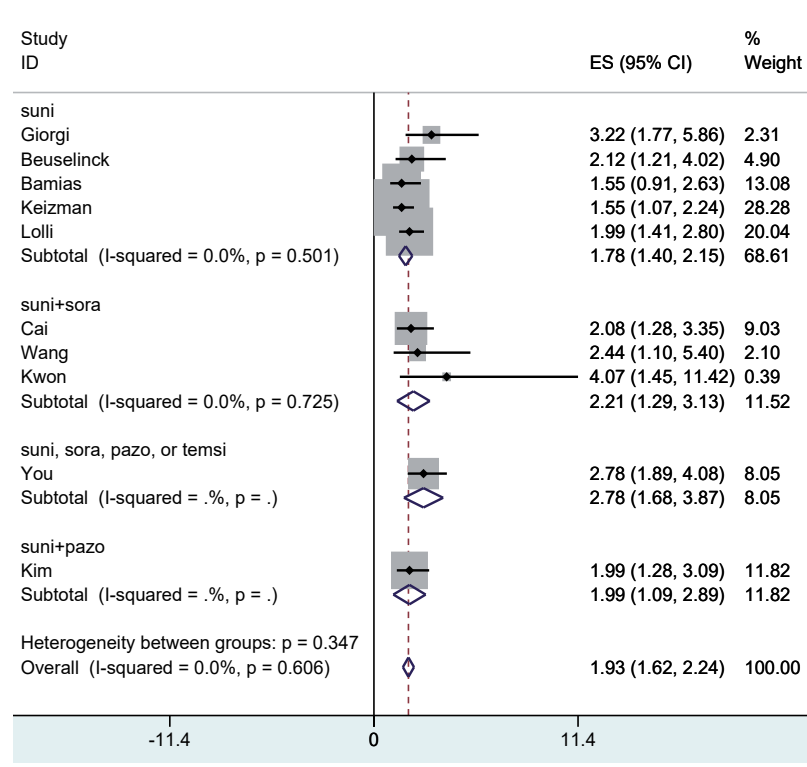

C

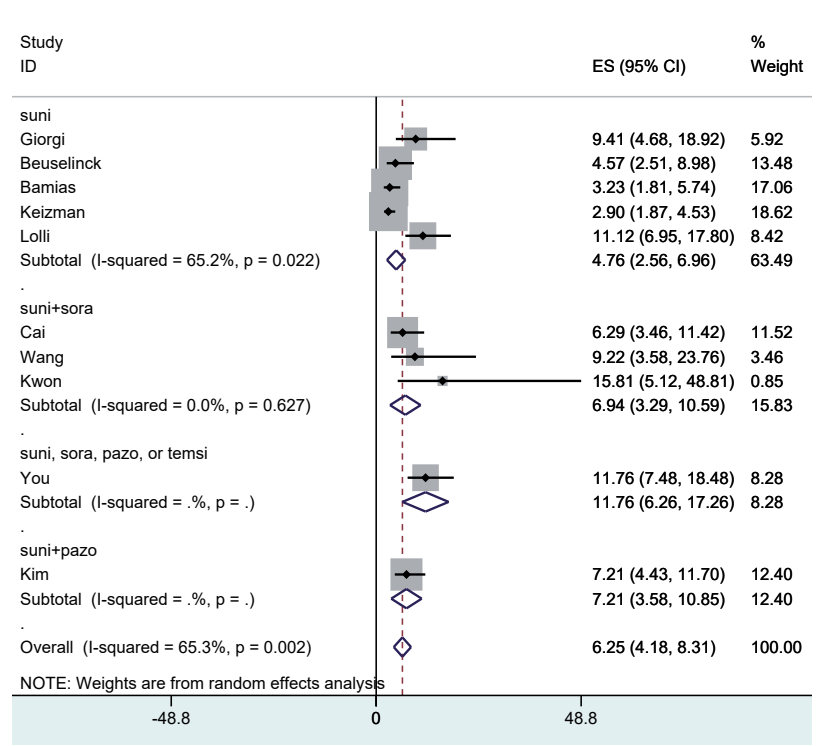

B

$\begin{array}{llll}\text { Study } & & & \% \\ \text { ID } & & & \\ \text { Weight }\end{array}$

D

\begin{tabular}{|c|c|c|c|}
\hline $\begin{array}{l}\text { Study } \\
\text { ID }\end{array}$ & & $\mathrm{ES}(95 \% \mathrm{Cl})$ & $\begin{array}{l}\% \\
\text { Weigh }\end{array}$ \\
\hline \multicolumn{4}{|l|}{ suni } \\
\hline Peltola & . & $2.34(1.30,4.22)$ & 20.57 \\
\hline Miyake & & $10.10(2.03,50.60)$ & 0.07 \\
\hline Keizman & - & $1.50(0.78,2.90)$ & 39.02 \\
\hline Subtotal $($ I-squared $=0.0 \%, p=0.527)$ & 0 & $1.80(0.94,2.66)$ & 59.66 \\
\hline \multicolumn{4}{|l|}{ suni+sora } \\
\hline Cai & $1 \rightarrow-$ & $6.43(3.35,12.36)$ & 2.16 \\
\hline Yao & $\leftarrow$ & $3.26(1.68,6.34)$ & 8.09 \\
\hline Lin & $\rightarrow$ & $4.32(2.05,9.10)$ & 3.53 \\
\hline Subtotal $(I-$ squared $=0.0 \%, p=0.464)$ & $\Delta$ & $4.03(2.25,5.81)$ & 13.78 \\
\hline \multicolumn{4}{|l|}{ evero } \\
\hline Auclin & - & $2.11(1.15,3.88)$ & 23.53 \\
\hline Subtotal $(\mathrm{I}$-squared $=. \%, \mathrm{p}=)$. & $\hat{Q}$ & $2.11(0.74,3.47)$ & 23.53 \\
\hline \multicolumn{4}{|l|}{ suni, sora, pazo, or temsi } \\
\hline You & $i \rightarrow$ & $7.47(4.38,12.72)$ & 2.53 \\
\hline Subtotal $(\mathrm{I}$-squared $=. \%, \mathrm{p}=)$. & & $7.47(3.30,11.63)$ & 2.53 \\
\hline \multicolumn{4}{|l|}{ suni+pazo } \\
\hline Kim & $\rightarrow$ & $6.54(2.10,20.80)$ & 0.50 \\
\hline Subtotal $(\mathrm{I}$-squared $=. \%, \mathrm{p}=)$. & & $6.54(-2.81,15.89)$ & 0.50 \\
\hline \multicolumn{4}{|l|}{ Heterogeneity between groups: $p=0.020$} \\
\hline Overall $(I-$ squared $=44.8 \%, p=0.070$ ) & 0 & $2.35(1.69,3.01)$ & 100.00 \\
\hline-50.6 & 0 & & \\
\hline
\end{tabular}

a) OS univariate analysis of intermediate to favorable risk group for area; b) OS univariate analysis of poor to favorable risk group for area; c) OS multivariate analysis of intermediate to favorable risk group for area; d) OS multivariate analysis of poor to favorable risk group for area. 